\begin{tabular}{|c|c|c|}
\hline $\begin{array}{l}\text { PKS } \\
\text { PUBLIC } \\
\text { KNOOLEDGE } \\
\text { PROJECT }\end{array}$ & $\begin{array}{c}\text { REVISTA DE GEOGRAFIA } \\
\text { (RECIFE) } \\
\text { http://www.revista.uffe.br/revistageografia }\end{array}$ & $\begin{array}{l}\text { OJS } \\
\frac{\text { OPEN }}{\text { JOUNAL }} \\
\text { SYSTEMS }\end{array}$ \\
\hline
\end{tabular}

\title{
GEOMORFOLOGIA E PLANEJAMENTO AMBIENTAL
}

\author{
Marcos José Nogueira de Sousa ${ }^{1}$ \\ ${ }^{1}$ Universidade Estadual do Ceará. Email: marcos.nogueira@uece.br \\ Artigo recebido em 17/07/2018 e aceito em 18/08/2018
}

\begin{abstract}
RESUMO
O trabalho tem o objetivo de demonstrar a aplicabilidade da geomorfologia para o planejamento ambiental. Parte-se de um conceito de geomorfologia por objetivos, apontando-se as relações interdisciplinares. Enfatiza-se o conceito tripartite da geomorfologia (AB' SABER, 1969) a serviço de pesquisas sobre o Quaternário, com as devidas adaptações. Considera a compartimentação topográfica e as formas de relevo de cada compartimento. Analisa a estrutura superficial da paisagem e contempla as questões subordinadas às condições morfogenéticas e aos processos morfodinâmicos atuais. Focaliza os procedimentos operacionais em trabalhos geomorfológicos e dá-se ênfase às bases para o planejamento ambiental, a saber: aplicações indiretas; avaliação prática das formas de relevo; estruturação e mapeamento de áreas de riscos; avaliação ecodinâmica do ambiente; planos de manejo; barramentos de rios e políticas de ordenamento territorial.
\end{abstract}

Palavras-chave: Geomorfologia, Planejamento Ambiental, Avaliação Ambiental, Sistemas Ambientais.

\section{GEOMORPHOLOGY AND ENVIRONMENTAL PLANNING}

\begin{abstract}
This study aims to demonstrate the applicability of geomorphology to environmental planning. The starting point is the concept of geomorphology oriented by objectives which points out the interdisciplinary relationships. It emphasizes the triple concept of geomorphology (AB 'SABER, 1969) supporting the research on the Quaternary, giving the appropriate adaptations. Topographic compartmentation and relief forms of each compartment are considered. The superficial structure of the landscape is analyzed and the questions regarding morphogenetic conditions and the current morphodynamic processes are investigated. This work focuses on the operational procedures on geomorphological works and emphasizes the bases for the environmental planning, namely: indirect applications; practical assessment of relief forms; risk areas mapping; ecodynamic evaluation of the environment; management plans; riverbeds and spatial planning policies.
\end{abstract}

Key-words: Geomorphology, Environmental Planning, Environmental Evaluation, Environmental Systems.

\section{INTRODUÇÃO}

A presente comunicação tem o propósito fundamental de demonstrar a aplicabilidade da geomorfologia para o planejamento ambiental. A geomorfologia, comparativamente com outras ciências da terra, a exemplo da geologia, da climatologia, da hidrologia, da pedologia, dentre outras, sofreu um certo retardamento em seu desenvolvimento e em relação às possibilidades de suas aplicações práticas.

Isso decorreu de especulações teóricas e de fragilidades metodológicas da geomorfologia clássica, incapazes de apreender os fatos naturais com suficiente precisão para 
agir sobre eles, conforme acentuava Tricart (1962). Fatos recentes contribuíram para valorizar e aperfeiçoar a pesquisa geomorfológica, fortalecendo as possibilidades de suas aplicações práticas para o planejamento. Pode-se destacar como alguns fatos relevantes os seguintes: a percepção sistêmica da natureza em detrimento de enfoques cartesianos; a valorização da multi-interdisciplinaridade; a percepção cientifica das relações de interdependência entre os componentes naturais; a utilização racional e a conservação dos recursos naturais, aliadas à proteção do meio ambiente como áreas estratégicas para o desenvolvimento sustentável; problemas associados com a gestão territorial; a expansão e a modernização da agropecuária; a conservação dos solos, da geodiversidade e da biodiversidade; as mudanças climáticas e a gestão dos recursos hídricos; a exacerbação dos processos erosivos em climas secos, agudizando a expansão da desertificação. São esses, dentre muitos outros, aspectos que requerem o conhecimento geomorfológico para o planejamento ambiental.

De modo inquestionável, a geomorfologia pode ter papel importante na busca de soluções para os problemas gerados pelas relações conflituosas, de causa e efeito, entre a sociedade e a natureza.

\section{ESTRUTURAÇÃO CONCEITUAL DE GEOMORFOLOGIA POR OBJETIVOS E PRINCIPAIS RELAÇÕES INTERDISCIPLINARES}

A Figura 1 expõe o conceito de geomorfologia a serviço de pesquisas sobre o Quaternário proposto por Ab' Saber (1969), com as devidas adaptações. O conceito tripartite evidencia, para cada uma das partes, os principais aspectos a serem abordados e as ciências que podem subsidiar a geomorfologia para cumprir seus objetivos. Os principais procedimentos operacionais são apresentados, justificando os meios utilizados para indicar as bases geomorfológicas para o planejamento ambiental, a serem subsequentemente discutidos. 
Figura 1- Relações Interdisciplinares nos estudos geomorfológicos e no planejamento ambiental.

\section{GEOMORFOLOGIA E PLANEJAMENTO AMBIENTAL}
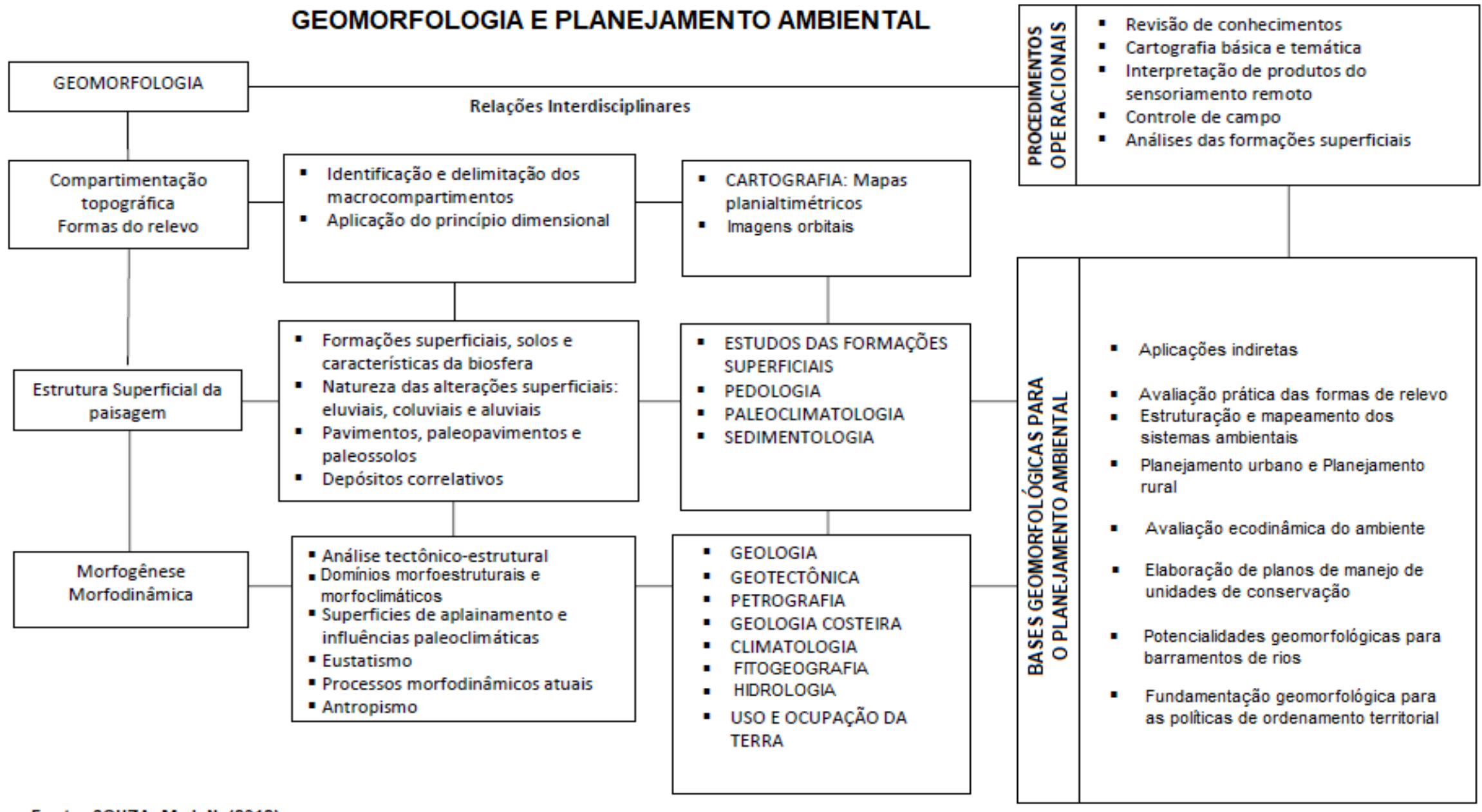

Fonte: SOUZA, M. J. N. (2018) 


\section{BASES GEOMORFOLÓGICAS PARA O PLANEJAMENTO AMBIENTAL}

Variadas são as aplicações que podem ser geradas pelo conhecimento geomorfológico para o planejamento ambiental. Essas aplicações dependem das relações interdisciplinares da geomorfologia, conforme sugerido na Figura 1.

A experiência brasileira em levantamentos sistemáticos de recursos naturais remonta à década de 80 do século passado (RADAMBRASIL, 1981). Subsequentemente, inumeráveis trabalhos têm demonstrado o enriquecimento contínuo das aplicações geomorfológicas ao planejamento. Associam-se não apenas à produção acadêmica, mas também de instituições oficiais (MMA, 1993; EMBRAPA, 1993).

O campo da geomorfologia para o planejamento ambiental, manifesta-se concretamente através da avaliação do aproveitamento prático das formas de relevo; do mapeamento de áreas dotadas de vulnerabilidades aos processos endógenos e exodinâmicos; de subsídios à conservação e proteção dos recursos naturais renováveis; na definição e delimitação de áreas de preservação ambiental; na implantação da infraestrutura viária e de complexos industriais; no planejamento urbano através do diagnóstico dos sítios naturais das cidades e com definição de áreas propícias ou limitativas para a expansão urbana; na delimitação de sistemas ambientais que constituem a base natural para Programas como o Zoneamento Agrícola, Planos de Manejo de Unidades de Conservação; na localização de áreas preferenciais para barramentos fluviais; na valorização de áreas pitorescas propícias ao turismo, dentre outras. Alguns desses aspectos serão discutidos ao longo do trabalho.

\section{- Aplicações indiretas}

As aplicações indiretas da Geomorfologia derivam de suas relações com disciplinas de domínio conexo. As formas de relevo derivadas de influências estruturais, refletem as características da estrutura geológica através das deformações tectônicas, do controle estrutural da rede hidrográfica, das variações litológicas condicionando as ações da erosão diferencial ou dos contatos geológicos manifestando-se através de rupturas topográficas. $\mathrm{O}$ comportamento geomorfológico é um guia imprescindível para a Fotogeologia que utiliza desde aerofotos até imagens orbitais, visando a preparação da cartografia geológica.

De modo similar, a geomorfologia presta subsídios importantes para a pedologia, também como componente guia para o mapeamento de solos através do uso de produtos de 
sensoriamento remoto. Não há como dissociar a evolução geomorfológica da maneira como os solos de distribuem através das catenas ou topossequências. Ou da distribuição das associações de solos conforme a compartimentação topográfica e das formas contidas nos diversos compartimentos. As características subordinadas ao uso dos solos, devem comtemplar a incidência dos processos morfogenéticos que operam sobre os solos, comprometendo sua qualidade e seu estado de conservação.

No âmbito da hidrologia a geomorfologia presta auxílios importantes, sendo o componente natural essencial para a delimitação das bacias hidrográficas. Interfere no escoamento, na distribuição e configuração dos padrões de drenagem, nos gradientes fluviais, nas possibilidades de aproveitamento dos recursos hídricos superficiais e na recarga dos aquíferos. As condições morfoestruturais são também condicionantes essenciais para justificar as disponibilidades ou deficiências de recursos hídricos, a exemplo do que se verifica na Chapada do Araripe e no Cariri Cearense. Na chapada, com cobertura de arenitos permoporosos da Formação Exu, há quase ausência de drenagem superficial. As camadas sotopostas impermeáveis que mergulham para Leste, ocasionam a proliferação de nascentes e fontes na encosta oriental da chapada. Elas dão origem aos cursos d'água cujos vales se espraiam pela depressão periférica meridional do Ceará para configurar o Cariri cearense.

Outras aplicações indiretas poderiam ser mencionadas. Por exemplo, ás variações climáticas locais; influências nos padrões fisionômicos e florísticos da vegetação; na estruturação dos sistemas ambientais ou geosistemas, conforme análises a serem posteriormente procedidas.

\section{- Avaliação prática das formas de relevo}

Essencialmente, busca-se avaliar o aproveitamento das geoformas com base em suas condições morfogenéticas; padrões de dissecação considerando as características dos interflúvios (formas aguçadas, convexas, tabulares); classes de declividades predominantes (desde planas até escarpadas); características da estrutura superficial da paisagem, incluindo espessura dos solos, natureza das alterações (eluviais, coluviais e aluviais), ocorrência de afloramentos e chãos pedregosos; processos morfodinâmicos atuantes, com destaque para os tipos de processos lineares (sulcos, ravinas e voçorocas) e areolares; problemas e riscos nos recursos florestais ( desmatamento, queimadas, ações erosivas), nos solos (desmatamento desordenado, sobrepastoreio, erosão acelerada), nos recursos hídricos 
(redução da vegetação dos mananciais, selamento superficial das áreas de recarga dos aquíferos, assoreamento).

\section{- Estruturação e mapeamento dos Sistemas Ambientais}

Os sistemas ambientais são integrados por variados componentes que mantêm relações mútuas entre si, sendo perpetuamente sujeitos às trocas de matéria e de energia. Os componentes são relativos ao suporte (litotipos, geoformas e águas subterrâneas), ao envoltório (clima e águas superficiais) e à cobertura (solos e biodiversidade).

As bases teórico-metodológicas para a estruturação dos mesmos são fundamentadas na concepção geossistêmica (Bertrand, 1976; Monteiro, 2000; Ross, 2016; Souza 2000, 2015 e Souza et al. 2009; Christopherson, 2012).

A delimitação dos sistemas tem o critério geomorfológico como referência de síntese do contexto geoambiental, especialmente no que tange à compartimentação topográfica e às feições morfoesculturais (Souza, 2015). Além de ser o componente mais estável dentre aqueles que têm a superfície da terra como campo de estudo, o relevo expõe as interações entre os demais componentes. Reflete as influências das deformações estruturais da crosta, motivadas por manifestações tectônicas. Exprime o escoamento hidrológico e configura a dispersão de drenagem através dos divisores de água. Pela disposição e orientação ou por influências altimétricas, o relevo justifica alterações climáticas locais, a exemplo dos enclaves úmidos do Nordeste, no domínio morfoclimático das caatingas. Condiciona a distribuição das topossequências e das associações de solos, com reflexos nos padrões fisionômicos e até florísticos da vegetação. A par de tudo isso, é o componente imediatamente visível na percepção interpretativa das imagens orbitais ou em mapas planialtimétricos. Desse modo, a categorização dos Sistemas e até sua denominação deve ser feita com base em topônimos do relevo ou da literatura geomorfológica.

Sendo os sistemas ambientais passíveis de uma delimitação cartográfica rigorosa e naturalmente dotados de condições geoecológicas diferenciadas, cabe distinguir os setores ambientais homogêneos. Eles representam, na classificação proposta por Bertrand (1972), aos geofácies que integram geossistemas oriundos da integração entre fatores do potencial ecológico e da exploração biológica.

Apresenta-se anexo a Figura 2 que trata da compartimentação geoambiental do Estado do Ceará com os principais sistemas ambientais. 
Figura 2- Compartimentação Geoambiental do Estado do Ceará

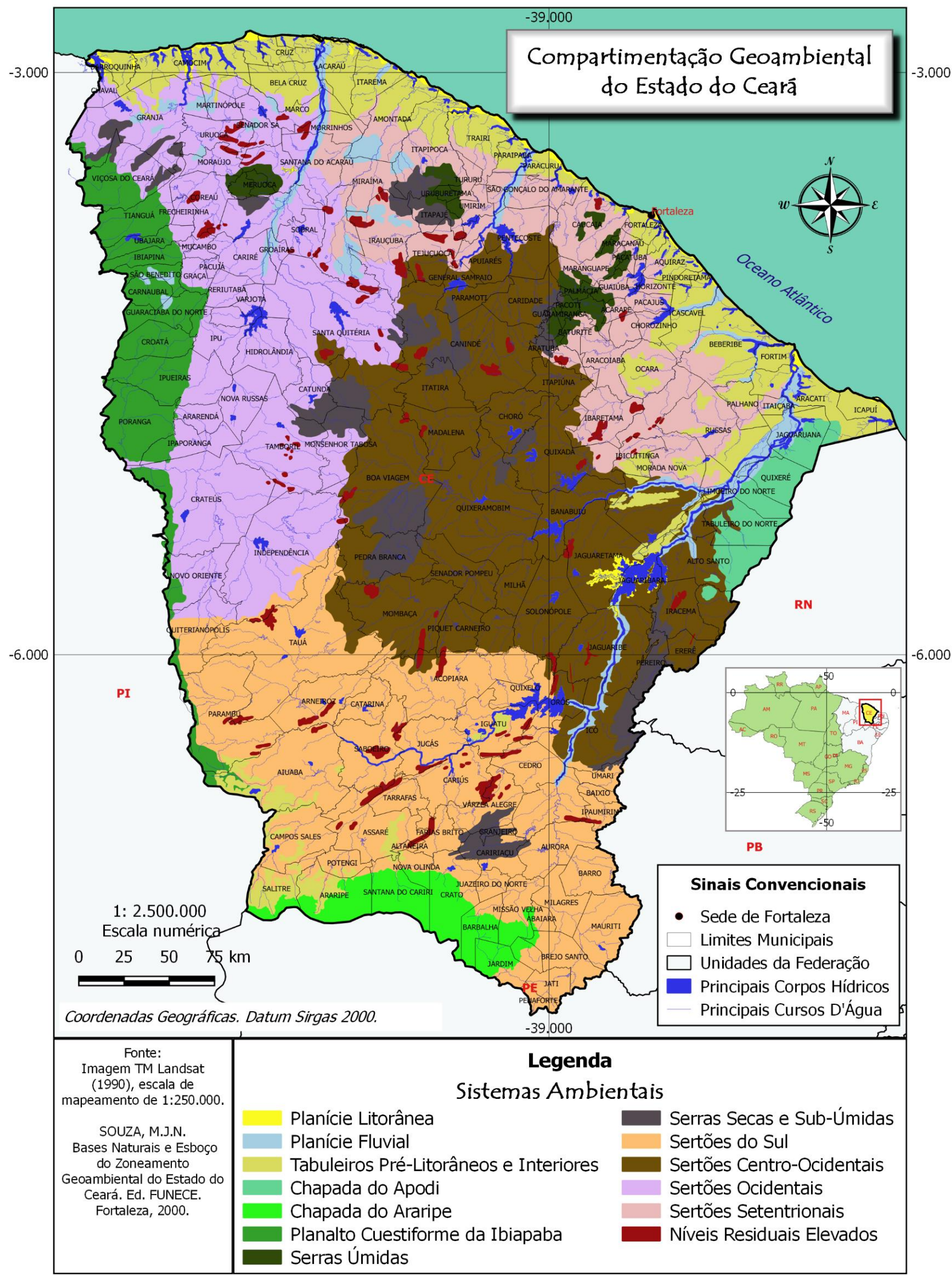

Fonte: Souza, 2018. 


\section{- Planejamento urbano e Planejamento rural}

A geomorfologia tem papel de expressiva importância para o planejamento urbano e para o planejamento rural.

Um dos aspectos importantes para o planejamento urbano, diz respeito às características naturais que servem de sítio para as cidades, o denominado sítio urbano. As características essenciais do sítio são de natureza geomorfológica e devem estar associados aos seguintes aspectos: localização da cidade em relação ao sistema ambiental e aos setores ambientais estratégicos anteriormente referidos; às características topográfica e geológicas das feições geomorfológicas; às condições hidroclimáticas, aos solos e à cobertura vegetal primária, via de regra, suprimida. Importante referir-se ao grau de estabilidade ecodinâmica do ambiente urbano, contemplando as vulnerabilidades ambientais que podem limitar a ocupação ou orientar a expansão. Para isso, cumpre relevar os chamados bens ambientais mais relevantes encontrados.

No caso de Fortaleza, capital do Estado do Ceará, elaborou-se o Diagnóstico Geoambiental do Município (Souza et al, 2009) para subsidiar o macrozoneamento ambiental e à revisão do Plano Diretor Participativo-PDPFor. A delimitação dos sistemas ambientais, procedida com base em critérios geomorfológicos, considerou a seguinte compartimentação: (1) Tabuleiros pré-Litorâneos; Planície Litorânea (faixa de praia, terraços marinhos, dunas móveis, dunas fixas, planícies flúvio-marinhas com manguezais); Vales (planícies fluviais, planícies lacustres, áreas de inundação sazonal); Morros Residuais; Faixa de Transição (tabuleiros/ depressão sertaneja). Dentre esses sistemas, há significativa predominância dos tabuleiros pré-litorâneos, demostrando a relativa estabilidade desse sistema e a baixa vulnerabilidade do sítio urbano de Fortaleza para a expansão da cidade. Ambientes vulneráveis e com maior instabilidade ecodinâmica estão localizados na planície litorânea e nos vales, com expressiva ocorrência de Áreas de Preservação Permanente (APP's), inadequadamente ocupadas.

O planejamento rural pode ser também subsidiado pelo conhecimento geomorfológico, conforme sugerido pelas aplicações indiretas, anteriormente expostas. Políticas públicas orientadas pelo Zoneamento Agroecológico (EMBRAPA, 1993), ou pelo Zoneamento Ecológico-Econômico dos Núcleos de Desertificação do Ceará (FUNCEME/DNOCS, 2013) partiu da identificação dos sistemas ambientais, delimitados por critérios geomorfológicos. Com base nas suas características associadas ao estado de 
conservação dos recursos naturais, da capacidade de suporte e na vocação de uso, propõem-se categorias variadas de zonas, tais como: Zona de Preservação Ambiental; Zona de Uso Sustentável; Zona de Recuperação Ambiental; Zona de Proteção Paisagística; Zona de Expansão Urbana.

\section{AVALIAÇÃO ECODINÂMICA}

O termo ecodinâmica foi proposto pelo geógrafo francês Jean Tricart (1977), para avaliar as condições de estabilidade/instabilidade dos sistemas ambientais. Segundo Tricart, o componente mais importante da dinâmica da superfície da terra é o morfogenético. Ele produz instabilidade e é um fator limitante muito importante para o desenvolvimento dos seres vivos e para a manifestação de processos exodinâmicos acelerados. Onde a morfodinâmica é intensa, há ausência de vegetação ou muito aberta e com biodiversidade pobre.

Outro componente a ser considerado é o pedogenético que conduz a uma evolução dos solos, permitindo o alcance de condições associadas à biostasia ou à fitoestasia. Há necessidade de considerar, também, as influências antrópicas e os níveis de degradação que daí decorrem.

Essas condições interferem na qualidade ambiental. Esta expressa o estado de conservação dos sistemas naturais e as tendências da sucessão ecológica. Essa sucessão pode tender para uma dinâmica progressiva ou regressiva. No primeiro caso, há alterações parciais e moderadas dos atributos e funções dos componentes naturais, derivando para níveis de qualidade ambiental satisfatórias nas sucessões ecológicas secundárias. Em condições de dinâmica regressiva, há alterações muito fortes dos atributos e funções dos componentes naturais, derivando para níveis de qualidade ambiental muito baixo ou desestabilizado nas sucessões ecológicas secundárias. As possibilidades de recuperação tendem para a inviabilidade ou para o estado de degradação.

A par dessas considerações, podem ser indicadas como categorias de meios ecodinâmicos os seguintes: meios medianamente estáveis, meio de transição ou "intergrades" e meios fortemente instáveis. Os meios medianamente estáveis têm cobertura vegetal suficientemente densa ou fechada para impedir eficazmente, ações associadas com a morfogênese mecânica; há dissecação moderada do relevo, sem maiores incisões fluviais, sem solapamentos vigorosos dos cursos d'água e vertentes com lenta evolução; tratam-se de regiões tectonicamente calmas desde longos tempos e ausência de manifestações vulcânicas e 
de sismicidade capazes de desencadear paroxismos de aspectos catastróficas; há nítida predominância da pedogênese sobre a morfogênese em face da incapacidade das ações morfodinâmicas em remover e transportar materiais.Os solos são maduros e espessos estando em estado de equilíbrio com os demais integrantes dos sistemas ambientais; o recobrimento vegetal primário é pouco alterado ou em franca regeneração, evoluindo para condições próximas às originais.

Os meios de transição ou "intergrades" posicionam-se entre os meios medianamente estáveis e fortemente instáveis. Marcam uma passagem gradual entre os mesmos. Conforme Tricart (1977), não existe nenhum corte abrupto, mas a presença de um "continuo" para marcar a transição entre estabilidade $X$ instabilidade. Admite que a caracterização desses meios depende da interferência permanente da morfogênese, exercendo-se de maneira concorrente sobre um mesmo espaço. Assim, o balanço pode favorecer uma ou outra: predominando a pedogênese passa-se aos meios medianamente estáveis; prevalecendo a morfogênese os meios tendem à forte instabilidade.

Os meios fortemente instáveis têm características opostas aos meios medianamente estáveis e a morfogênese é o elemento predominante da dinâmica natural. Apresentam cobertura vegetal ausente ou meio aberta e as influências dos processos morfodinâmicos impostos pelo clima são diretas; a geodinâmica interna é muito instável, intervindo através de ações variadas, como por exemplo, o vulcanismo através das corridas de lavas ou de cinzas que têm efeitos imediatos catastróficos sobre o ambiente; relevos fortemente dissecados e com altas classes de declives que impedem a pedogênese; ausência ou adelgaçamento muito forte dos solos e grande frequência de caos de blocos e de chãos pedregosos; climas com influências morfodinâmicas muito agressivas, como no caso dos climas secos que aliados às atividades antrópicas inapropriadas, podem conduzir à instalação e expansão da desertificação.

\section{ELABORAÇÃO DE PLANOS DE MANEJO DE UNIDADES DE CONSERVAÇÃO}

O plano de manejo é um documento técnico mediante o qual, com fundamento nos objetivos gerais das Unidades de Conservação (Unidades de Proteção Integral e Unidades de Uso Sustentável), se estabelece o seu zoneamento e as normas que devem presidir o uso da área e o manejo dos recursos naturais. Trata-se de um instrumento de planejamento e gerenciamento elaborado de acordo com a avaliação dos fatores abióticos, bióticos e 
antrópicos existentes. Com base no zoneamento apresentado, que parte da indicação dos sistemas - cujo critério guia é de natureza geomorfológica- são estabelecidas ações de manejo. Elas devem ser capazes de manter a qualidade ambiental da Unidade de Conservação e sua sustentabilidade. No Estado do Ceará, tivemos a oportunidade de coordenar a elaboração de diversos planos em que houve efetiva participação da comunidade através das oficinas de planejamento (Souza et al, 2005).

\section{POTENCIALIDADES GEOMORFOLÓGICAS PARA BARRAMENTOS DE RIOS}

Na evolução geomorfológica do Neógeno ao Quaternário, particularmente no Nordeste brasileiro, desenvolveram-se superfícies de erosão escalonadas. Elas marcaram também os registros de flutuações climáticas onde alternavam-se características associadas à predominância de dissecação (climas úmidos) e de pediplanação (climas secos). Nas transições entre as superfícies, formaram-se inumeráveis gargantas epigênicas (boqueirões) oriundas de ações fluviais exacerbadas, resultando em importantes pontos para barramentos de rios no semiárido Nordestino, a exemplo, de grandes açudes como Castanhão, Orós (Ceará), Açu (Rio Grande do Norte), Mãe d'água (Paraíba).

\section{FUNDAMENTAÇÃO GEOMORFOLÓGICA PARA O ORDENAMENTO TERRITORIAL}

O ordenamento territorial ou do espaço regional constitui uma das áreas estratégicas da concepção do desenvolvimento sustentável. No Brasil, um dos programas prioritários para o ordenamento territorial é o Zoneamento Ecológico-Econômico admitido também como Zoneamento Ambiental. Divide-se o território em zonas, conforme as necessidades de proteção, conservação e recuperação dos recursos naturais e do desenvolvimento sustentável.

Os sistemas ambientais compõem a base natural para o estabelecimento das zonas e o critério geomorfológico é guia de delimitação, conforme precedentemente referido. A Figura 3 sintetiza o conjunto de procedimentos metodológicos considerados para o zoneamento. 
Figura 3- Procedimentos metodológicos

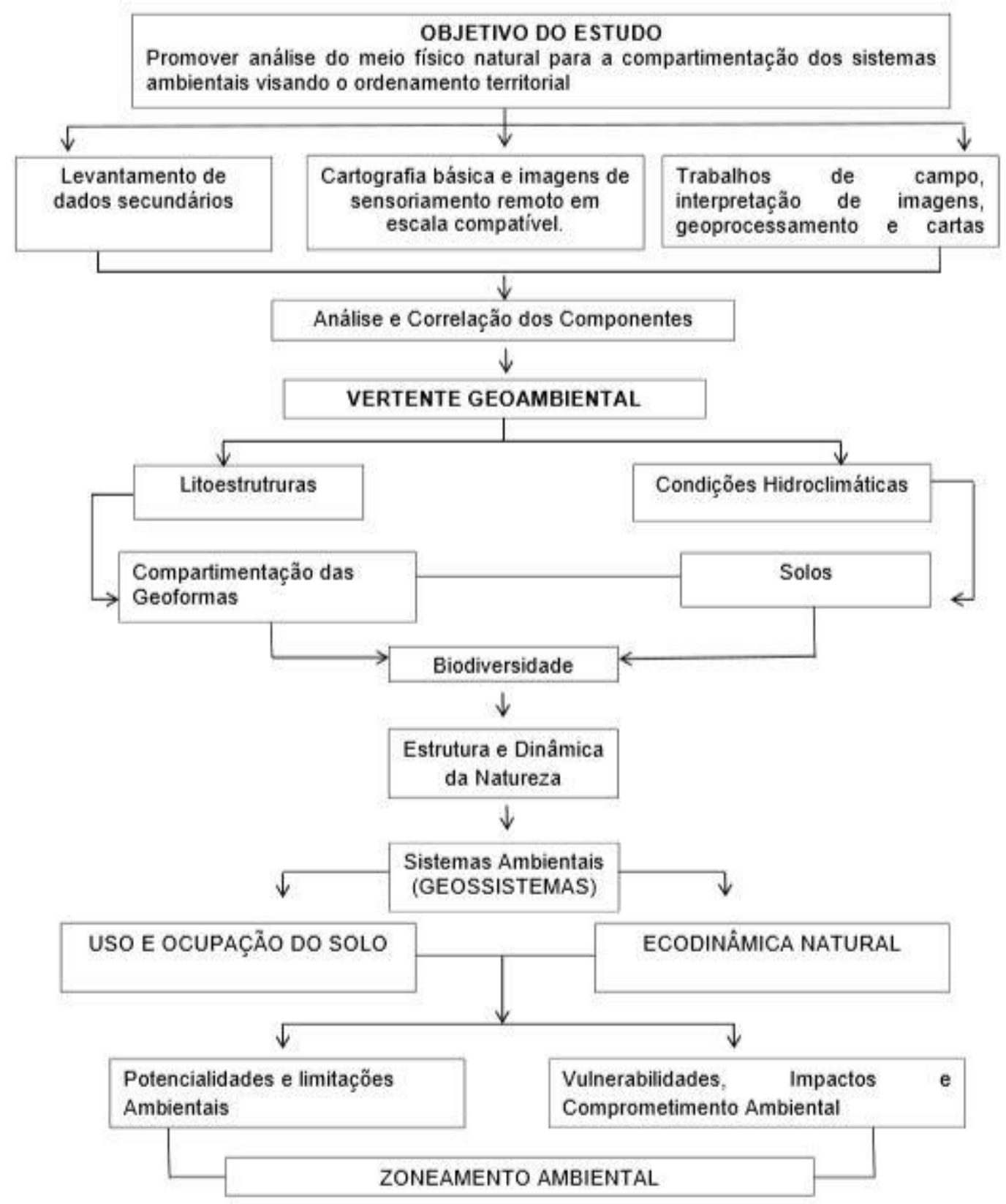

Fonte: Souza, 2018.

\section{CONSIDERAÇÕES FINAIS}

As possibilidades de aplicações práticas da geomorfologia para o planejamento têm sido cada vez mais evidentes. Este fato é enaltecido quando as relações interativas com outras ciências da terra se efetivam, principalmente com aquelas que têm a superfície da terra como campo de estudo. Como ciência de síntese, o objeto formal de estudo da geomorfologia sofre 
e reflete influências geológicas, pedológicas, hidroclimáticas, ecológicas e de outras ciências naturais.

Aborda temas de interesse socioambiental, estando apta para a solução de problemas derivados da relação conflituosa ou harmônica da sociedade com a natureza. Isso pode ser feito através da avaliação prática das formas de relevo, de suas aplicações indiretas, de subsídios ao planejamento rural e urbano, da delimitação de geossistemas e/ou ecossistemas, de contribuições ao ordenamento territorial e da elaboração de planos de manejo de Unidades de Conservação de Proteção Integral ou de Uso Sustentável.

É, oportuno assinalar, enfim, que o campo de ação da geomorfologia se expande através de novos procedimentos técnicos que poderão enriquecer as significativas possibilidades de aplicações práticas da geomorfologia para o planejamento ambiental.

\section{REFERÊNCIAS}

Ab'Saber, A. N. Um conceito de geomorfologia a serviço de pesquisas sobre o quaternário. São Paulo: IGEOG-USP, 1969 (Geomorfologia, nº 18).

BERTRAND, G. Paisagem e geografia física global: esboço metodológico. Tradução Olga Cruz - Caderno de Ciências da Terra. Instituto de Geografia da Universidade de São Paulo, $\mathrm{n}^{\circ} 13,1972$.

BRASIL. EMBRAPA. Zoneamento Agroecológico do Nordeste. Petrolina, PE, 1993. Ministério do Meio Ambiente. Programa Zoneamento Ecológico- Econômico: ZEE do baixo Parnaíba. Brasília -DF, 2002 (Relatório Final).

. Ministério das Minas e Energia. Projeto RADAMBRASIL. Folha SA24 (Fortaleza); folha SD 24/25 Jaguaribe/Natal. Levantamento de Recursos Naturais. Rio de Janeiro, 1981.

Ministério das Minas e Energia. Programa Zoneamento Ecológico-Econômico: Diretrizes Metodológicas para Zoneamento Ecológico-Econômico do Brasil. MMASecretaria de Políticas para o Desenvolvimento Sustentável. Brasília-DF, 2001.

CHRISTOPHERSON, R.N. Geossistemas- uma introdução à geografia física. $7^{a}$ edição. Porto Alegre: Bookman, 2012.

MONTEIRO, C.A.F. Geossistemas: História de uma procura. São Paulo. Contexto. 2000. ROSS, J. L. S. Ecogeografia do Brasil: Subsídios para o planejamento ambiental. São Paulo. Oficinas de texto, 2009, 208p.

SOUZA, M. J. N. de. Contribuição ao estudo de unidades morfo-estruturais do Estado do Ceará. Revista de Geologia v. 1/DEGEO/UFC, Fortaleza, 1988, p.73-91. 
Bases Naturais e Esboço do Zoneamento Geoambiental do Estado do Ceará. In: LIMA, L. C; SOUZA, M. J. N; MORAES, J. O. Compartimentação territorial e gestão regional do Ceará. Fortaleza: FUNECE. 2000.p.13-98.

; (coordenador) et al. Planos de Manejo das Áreas de Proteção Ambiental do Estado do Ceará (diversos): Superintendência Estadual do Meio Ambiente - Fortaleza: SEMACE/IEPRO, 2005.

; OLIVEIRA, Vládia Pinto Vital de. ANÁLISE AMBIENTAL-UMA PRÁTICA DA INTERDISCIPLINARIDADE NO ENSINO E NA PESQUISA. Revista Eletrônica do Prodema. Fortaleza, v. 7, n.2, p. 42-59, nov. 2011.

; Mapeamento de Sistemas Ambientais e Aplicações Práticas para a Conservação da Natureza e o Ordenamento Territorial. In: Revista Equador (UFPI), Vol. 4, no 3, (2015). Edição Especial. XVI Simpósio Brasileiro de Geografia Física Aplicada. Teresina, 2015. TRICART, J. Ecodinâmica. Rio de Janeiro: IBGE/SUPREN, 1977. p. 91. 